4

17 Author Note: The $3^{\text {rd }}$ through $7^{\text {th }}$ authors contributed equally to the completion of this manuscript

18 and are listed in alphabetical order. The authors have no financial and/or personal relationships

19 that influenced this work.
Travis E. Dorsch ${ }^{1}$, Alan L. Smith², Jordan A. Blazo ${ }^{3}$, Jay Coakley ${ }^{4}$, Jean Côté ${ }^{5}$, Christopher R. D. Wagstaff ${ }^{6}$, Stacy Warner ${ }^{7}$, \& Michael Q. King ${ }^{1}$

${ }^{1}$ Utah State University: Logan, Utah, USA

${ }^{2}$ Michigan State University: East Lansing, Michigan, USA ${ }^{3}$ Louisiana Tech University: Ruston, Louisiana, USA ${ }^{4}$ University of Colorado-Colorado Springs: Colorado Springs, Colorado, USA ${ }^{5}$ Queens University: Kingston, Ontario, Canada ${ }^{6}$ University of Portsmouth: Portsmouth, Hampshire, England ${ }^{7}$ East Carolina University: Greenville, North Carolina, USA 
Abstract

25 The aim of the present paper was to outline a heuristic model that facilitates movement toward

26 an integrated understanding of the youth sport system. We define the youth sport system as the

27 set of interdependent persons and contexts that influence and are influenced by an athlete in

28 youth sport. Our model builds directly from a systems perspective, and its tenets of holism,

29 feedback loops, and roles (Broderick, 1993; von Bertalanffy, 1972). Specifically, we argue that

30 the persons and contexts that surround an athlete in youth sport should be examined collectively,

31 self-correct over time, and take on certain functions that are negotiated over time. The model

32 extends past contributions toward integration (e.g., García Bengoechea, 2002) by outlining how

33 proximal and distal processes within youth sport can be studied in a more unified way. Looking

34 forward, research designed to capture the nuanced ways persons and contexts influence and are

35 influenced by one another in youth sport will be best positioned to impact theory and practice in 36 meaningful ways.

38 Keywords: youth sport, athlete development, systems theory, pediatric kinesiology 


\section{Toward an Integrated Understanding of the Youth Sport System}

Youth sport is perhaps the most common extracurricular activity across the world, with

41 most young people participating in structured or unstructured sport activities during childhood

42 and adolescence (Hulteen et al., 2017). Youth sport participation has been linked to numerous

43 physical, psychological, emotional, social, and intellectual benefits, but also has been associated

44 with negative outcomes such as risk-taking, eating disorders, low self-esteem, aggression, and

45 decreased morality (Fraser-Thomas et al., 2005). The extent to which youth experience positive

46 or negative outcomes in sport is influenced by their interactions with others as well as the

47 broader contexts in which their participation occurs (García Bengoechea \& Johnson, 2001).

Despite extensive research addressing the many persons and contexts that surround youth

49 in sport, few scholars have attempted to generate an integrated understanding of the youth sport

50 system. This is surprising because fields such as communication, human development,

51 kinesiology, psychology, sport management, and others contribute to this interdisciplinary area

52 of inquiry. One attempt at integration was made by García Bengoechea (2002), who argued that

53 processes (e.g., coaching, parenting, peer interactions), personal characteristics (e.g., an athlete's

54 age, gender, and ability), contextual factors (e.g., an athlete's level of participation), and time

55 (e.g., the athlete's stage of maturation, the duration of a salient relationship) influence young

56 athletes' developmental experiences in sport. This conceptual perspective aligned with calls to

57 employ more dynamic models of reciprocal causation in sport (e.g., Brawley \& Martin, 1995), as

58 well as broader theorizing in the human development literature (e.g., Bronfenbrenner's 2005

59 process-person-context-time framework).

Although it is important to examine the dynamic and reciprocal processes that influence

61 youth development in sport, it also remains essential to acknowledge the interconnectedness of 
62 these processes across a range of persons and contexts. Researchers interested in family

63 dynamics have examined athletes' interactions with parents and/or siblings, those interested in

64 team dynamics have examined athletes' interactions with coaches and/or peers, and others have

65 examined the role structural factors play in youth sport. Such work has done much to extend

66 youth sport knowledge, yet has not captured the interconnected nature of the persons and

67 contexts that may reciprocally influence one another. A systems lens (von Bertalanffy, 1972;

68 Broderick, 1993) has the potential to guide researchers in capturing this interconnection by

69 enabling the examination of a broad range of social relationships and the ways these

70 relationships may shape or be shaped by the contexts in which persons interact. This affords

71 scholars the opportunity to highlight the extensive web of dynamic and reciprocal relationships

72 that define the youth sport system.

73 Here we define the youth sport system as the set of interdependent persons (i.e., parents,

74 siblings, peers, and coaches) and contexts (i.e., organizations, communities, and societies) that

75 have the potential to influence or be influenced by an athlete's behaviors, attitudes, experiences,

76 and outcomes in youth sport. Over the course of a young athlete's development, persons and

77 contexts interact systematically and change in relative salience from toddlerhood through

78 middle-to-late adolescence (Côté \& Vierimaa, 2014). The systems perspective (von Bertalanffy,

79 1972; Broderick, 1993) consists of several tenets that can help us better understand the youth

80 sport system.

81 A primary tenet of the systems perspective is holism, which stresses that the persons and

82 contexts that surround an individual should be viewed collectively rather than independently

83 (Broderick, 1993). In youth sport, athletes' interactions within the family and team, as well as

84 with the broader contexts that surround them, should be seen as constituting a dynamic, 
85 reciprocal, intricate, and sometimes coordinated system rather than as independent, top-down

86 influences on the athlete. A second tenet of the systems perspective is that the persons and

87 contexts that constitute a system participate in feedback loops, whereby self-corrections occur

88 based on interactions with other persons and contexts within the system. For example, families

89 and youth sport teams have the capacity to change course (e.g., offer feedback, discontinue

90 participation, start a new team or league) if the contexts in which sport takes place do not align

91 with their goals. Lastly, an important assumption specific to the systems perspective is that the

92 persons and contexts that constitute a system will take on certain roles that are negotiated over

93 time (see Smith \& Hamon, 2012). For example, the roles that persons play in youth sport vary

94 across organizations, and the roles that organizations play in youth sport vary across

95 communities and societies. These three tenets can help researchers from a range of disciplines

96 better understand how persons and contexts may influence or be influenced by athletes'

97 behaviors, attitudes, experiences, and outcomes in youth sport.

98 Given the international proliferation of youth sport research over recent decades (see

99 Gould, 2019), it is fitting that empirical knowledge across multiple areas of the youth sport

100 literature has systematically deepened. Given this growth of knowledge, it is not surprising that

101 many scholars have narrowed their focus to more targeted areas of understanding. While this

102 narrowing has led to deeper consideration of the roles of parents, siblings, peers, and coaches, as

103 well as the organizations, communities, and societies in which young athletes engage, an

104 unintended consequence has been the construction of empirical "silos" that often remain

105 independent of one another (see Duda, 1999; Schary \& Cardinal, 2015). Therefore, a need exists

106 to establish a conceptual framework that helps youth sport scholars move toward thoughtful

107 integration of the core areas of knowledge about youth sport. The process of pursuing this 
108 integration has the potential to foster a range of interdisciplinary collaborations resulting in new

109 and important research questions and discoveries. This is likely to yield a more nuanced

110 understanding of the youth sport system.

111 The aim of the present paper is to outline a heuristic model that facilitates movement

112 toward an integrated understanding of the youth sport system. Heuristic models are early

113 practical and flexible frameworks that offer a working understanding of a specific area of inquiry

114 and that are useful in catalyzing theory development. In the subsequent sections, we briefly detail

115 how the family subsystem (comprised of an athlete, parents, and siblings), the team subsystem

116 (comprised of an athlete, peers, and coaches), and the environmental subsystem (comprised of

117 organizations, communities, and societies) have the potential to impact athletes' behaviors,

118 attitudes, experiences, and outcomes in youth sport. Our model integrates these three subsystems

119 and highlights some novel questions that could be tested by future scholars from a range of

120 disciplines. Although we identify elements within and links across the persons and contexts in

121 the model, we do not assume the model is inclusive of all possibilities, unchanging, or equally

122 applicable across all athletes, families, teams, or environments.

123 In presenting the model, we extend past contributions toward theoretical integration (e.g.,

124 García Bengoechea, 2002) by outlining how proximal (e.g., parent pressure and support, sibling

125 modeling and differentiation, peer social comparison and expectations, coach-relationships and

126 leadership) and distal (e.g., organizational culture and standards, community infrastructure and

127 access, societal traditions and values) aspects of the youth sport system can be studied in a more

128 integrated way. Our model has the potential to inform scholars who wish to examine the

129 intersections of persons and contexts in youth sport. Specifically, we hope to facilitate systemic

130 and interdisciplinary understanding of the youth sport system across a range of settings. This 
131 offers the potential to inform practitioners who are charged with designing youth sport contexts

132 and shaping the daily interactions that occur among young athletes and their parents, siblings,

133 peers, and coaches.

\section{The Family Subsystem in Youth Sport}

The first component of the youth sport system is the family subsystem. The family is the

136 most proximal - and in many cases most salient - subsystem with regard to athlete behaviors,

137 attitudes, experiences, and outcomes, especially in the earliest years of sport participation (Côté,

138 1999), and has been shown to have lasting impacts (Dixon et al., 2008). Thus, researchers from

139 various disciplines have targeted families as an important reference point for understanding the

140 development of athletes in sport and physical activity settings (e.g., Brustad, 2010). Two primary

141 family members who have the potential to influence and be influenced by athletes in youth sport 142 are parents and siblings.

143 As co-participants and important socialization agents in youth sport, parents are essential 144 contributors to the behaviors, attitudes, experiences, and outcomes of young athletes (Babkes \& 145 Weiss, 1999; Côté, 1999; Fredricks \& Eccles, 2004). Although researchers have extensively 146 explored parent-child interactions in youth sport (see Dorsch et al., 2019), few have examined 147 parents' roles as co-participants in the broader youth sport system. That is, much of this research 148 has considered parents as providers and interpreters of the youth sport experience without fully 149 acknowledging the many factors within the family, within the athlete's team, and across the 150 contexts in which an athlete participates that have the potential to influence and/or be influenced 151 by parent involvement. This is an important consideration, given recent ecological understanding 152 of parents' development in youth sport (Dorsch et al., 2015a; Holt et al., 2008). Whereas a rich 153 literature describes the influence of parents on young athletes, across various national contexts, it 
154 is also important for researchers to consider the many ways persons and contexts may shape

155 parents' involvement in youth sport. For example, through a developmental lens, parents' roles

156 in youth sport are often driven by the changing characteristics of the athlete (e.g., age, gender,

157 ability), the organizational or community context (e.g., missions, standards, initiatives, and

158 support), and the societies in which the athlete participates (e.g., resources and policy). These

159 factors are dynamic and may shape the nature and development of parents' goals for their

160 children vis-à-vis the parent-child sport relationship and how parents are involved in their

161 children's participation on a day-to-day basis (Dorsch et al., 2015b; Knight \& Holt, 2014). This

162 assertion aligns with Côté and colleagues' developmental model of sport participation, which

163 highlights the dynamic nature of parent roles and involvement patterns in youth sport (Côté,

164 1999; Côté \& Vierimaa, 2014). In addition to these external factors, parents' person

165 characteristics as set forth in Bronfenbrenner's (2005) PPCT model of human development (e.g.,

166 gender, sport experiences, parenting style) also shape the roles they assume and goals they adopt

167 for their children in sport (Dorsch et al., 2015a; Holt et al., 2008).

168 To optimize parents' roles as socialization agents in youth sport, scholars and

169 practitioners have sought to shape parent involvement in ways that limit athlete perceptions of

170 parental pressure and facilitate athlete perceptions of parental support (e.g., Harwood \& Knight,

171 2015). In line with this work, researchers have begun to document strategies that can be used to

172 engage parents in evidence-based learning (e.g., Dorsch et al., 2017; Thrower et al., 2017). Given

173 the multiple roles that parents hold, they have described feeling ill-equipped to optimally interact

174 with their children in youth sport (see Harwood \& Knight, 2015). Accordingly, parents have

175 been shown to: (a) seek the help of extended family, friends, and community members to meet

176 the time demands of youth sport (Burgess et al., 2016), (b) draw on the professional and 
177 interpersonal knowledge of coaches to begin to understand the needs of their children and the

178 technical aspects of the sport (Knight \& Holt, 2014), and (c) encourage their children to model

179 siblings and build relationships with peers to manage the physical and emotional demands of

180 sport (Knight \& Holt, 2014). It is important, therefore, to acknowledge that parents are an

181 integral part of the family subsystem and the larger youth sport system (Teques et al., 2018).

182 The developmental significance of siblings in youth sport is understudied, yet holds much

183 promise for helping build a holistic picture of the family subsystem and broader youth sport

184 system. Although siblings have attributes in common with many interpersonal relationships, they

185 also possess unique characteristics and developmental importance (Cicirelli, 1995). For example,

186 the sibling relationship is often marked by competition and cooperation, modeling and

187 differentiation, social comparison, and experiences of compassion (Furman \& Buhrmester, 1985).

188 The potential depth and varied experiences of this relationship can be important to the roles

189 siblings play in shaping each other's social, emotional, and cognitive development (Yeh \&

190 Lempers, 2004). Moreover, siblings can be developmentally salient in tandem with other social

191 agents such as parents and peers (e.g., Bell et al., 1985; Fagan \& Najman, 2005). This is notable

192 considering prevailing evidence that parents are the primary providers and interpreters of youth

193 sport, and the documented increase in the salience of peers as a proxy for family during late

194 childhood and early adolescence (Duncan et al., 2005; Savin-Williams \& Berndt, 1990).

195 Importantly, sibling interactions are thought to foster social comparison and social-cognitive

196 development, providing a foundation for relationships with other peers (Dunn, 2007; McHale et

197 al., 2012). Given that sibling interactions are consequential to development, siblings may

198 influence one another's participation in, and affective responses to, structured and unstructured

199 sport (Horn \& Horn, 2007). 
Researchers recently have begun to explore the roles of siblings in sport (see Blazo \&

201 Smith, 2018). Examples of this work include the experience of having an athletically gifted

202 sibling in the household (Blazo et al., 2014; Newhouse-Bailey et al., 2015) and socialization into

203 and continued involvement in sport (e.g., Osai \& Whiteman, 2017; Ziviani et al., 2006). Results

204 of this work suggest that young athletes engage in sibling processes such as modeling and

205 differentiation that shape their sport-related behaviors, attitudes, experiences, and outcomes. As

206 researchers seek to integrate these and other topics via sustained lines of investigation,

207 theoretically- and developmentally-informed studies that view siblings as a component of the

208 family subsystem and the broader youth sport system are needed.

\section{The Team Subsystem in Youth Sport}

210 The second component of the youth sport system is the team subsystem. The team is

211 considered proximal to the athlete and becomes especially important during adolescence, when

212 transitioning to sport contexts that are less often directed by parents (Côté, 1999). Two primary

213 persons within the team subsystem who may influence or be influenced by athletes are peers and

214 coaches.

215 Peers are essential yet relatively underappreciated contributors to athletes' behaviors,

216 attitudes, experiences, and outcomes in youth sport. Whereas most researchers exploring social

217 dynamics in sport have focused on coaches and parents, there have also been efforts focused on

218 peers (Smith et al., 2019; Weiss \& Stuntz, 2004). There is much value to examining peers in

219 youth sport because, as youth move into more intensive participation during adolescence,

220 relationships with fellow participants can become a proxy for family. Peers serve as an important

221 reference for social comparison, spend extensive periods of time together, fulfill various 
222 relational functions, and often hold relatively equal power to one another as compared to parents,

223 coaches, and other adults (Smith et al., 2019).

224 The empirical literature on peers in youth sport varies across countries and cultures,

225 though some persistent streams of inquiry are evident. There is a well-established link between

226 competence and social acceptance in sport (Evans \& Roberts, 1987; Weiss \& Duncan, 1992),

227 and sport can foster the cultivation and expression of friendships (Weiss et al., 1996; Weiss \&

228 Stuntz, 2004) and social identity (Bruner et al., 2017). At the same time, high-performance sport

229 contexts that are competitive in nature can challenge the development of authentic relationships

230 (Adams \& Carr, 2019), introduce conflict among peers that needs to be managed (Holt et al.,

231 2012), and even involve the victimization of some participants (Partridge \& Knapp, 2016). Thus,

232 a young athlete's sport involvement can serve as a pathway to positive social outcomes or to

233 diminished social standing and well-being, suggesting that youth sport is a form of social

234 currency (Nicholson et al., 2013). The motivational climate reinforced by peers also has been

235 shown to be salient in youth sport (McLaren et al., 2016; Smith et al., 2010; Vazou et al., 2006)

236 as have peer relation-inferred self-efficacy (i.e., RISE) perceptions (Jackson et al., 2007; Jackson

237 et al., 2014). Collectively, the extant literature offers evidence of the importance of teammates

238 and competitors in youth sport and suggests that peers should be considered in any broader

239 treatment of the youth sport system.

240 Initial steps to integrate understanding of peers' contribution to the youth sport system

241 can be found in research designed to consider multiple persons simultaneously with respect to

242 social motivation, well-being, or other outcomes. Efforts of this nature have been conducted that

243 examine peers along with parents (e.g., Ullrich-French \& Smith, 2006), coaches (Gardner et al.,

244 2016; Riley \& Smith, 2011), and teachers (Cox \& Ullrich-French, 2010). Exploring relationships 
245 or interactions among people is challenging and complex. However, it is essential to pursue such

246 work and capture the integration of persons and contexts, as is advocated in systems theory (von

247 Bertalanffy, 1972; Broderick, 1993).

248 Coaches have the potential to influence and be influenced by athletes' behaviors,

249 attitudes, experiences, and outcomes in youth sport, and several conceptual models have been

250 developed to better understand the coach's role in youth sport (e.g., Chelladurai, 2007; Côté et al.,

251 1995; Jowett, 2005; Smith \& Smoll, 2002). These models have emerged from a range of

252 countries and are grounded in different literatures, including leadership, expertise, coaching,

253 motivation, and education. In a review of these models and the broader coaching literature, Côté

254 and Gilbert (2009) proposed a succinct, yet comprehensive, definition of coaching effectiveness:

255 "The consistent application of integrated professional, interpersonal, and intrapersonal

256 knowledge to improve athletes' competence, confidence, connection, and character in specific

257 coaching contexts" (p. 316). This integrative definition frames effectiveness as coaches' ability

258 to exhibit professional and interpersonal behaviors that foster positive developmental outcomes

259 in their athletes. Studies of coaches in various sports show an association between coaches'

260 effective behaviors and athletes' outcomes such as enjoyment, competence, persistence,

261 teamwork, and initiative (e.g., Álvarez et al., 2009; Coatsworth \& Conroy, 2009; Erickson \&

262 Côté, 2016; Pelletier et al., 2001).

263 Importantly, coaching requires consistent interactions with others within the family and

264 team subsystems (e.g., parents, siblings, peers, and other coaches). Because these interactions are

265 embedded within organizations, communities, and societies, coaching research would benefit

266 from efforts to generate a more holistic understanding of the complex factors that are linked to

267 coaching effectiveness. This is consistent with a systems approach, which suggests development 
268 takes place via interactions among interrelated persons within salient developmental contexts 269 (Broderick, 1993).

$270 \quad$ Viewing coaches within the team subsystem and the broader youth sport system

271 necessitates a nuanced conceptualization of coaching processes. Examples of how to integrate

272 understanding of coaching effectiveness can be seen in the way coaches are expected to build

273 and maintain relationships. Specifically, research has been conducted on parent-coaches (e.g.,

274 Weiss \& Fretwell, 2005), the coach-athlete relationship (e.g., Horne \& Carron, 1985; Olympiou

275 et al., 2008), and the parent-athlete-coach triangle (e.g., Hellstedt, 1987; Jowett \& Timson-

276 Katchis, 2005). Although this research has been designed to capture dyadic - and in some cases

277 triadic - relationships, it could be extended to integrate psychological, behavioral, and affective

278 processes and outcomes that occur within and across the family, team, and environmental

279 subsystems. This would be similar to the recent work from Canada examining transformational

280 leadership among youth sport coaches (e.g., Turnnidge \& Côté, 2017). Moving forward,

281 conceptually-driven efforts to pursue such extensions would advance holistic understanding of

282 the youth sport system.

\section{The Environmental Subsystem in Youth Sport}

The third component of the youth sport system is the environmental subsystem. This is

285 considered a distal subsystem with reference to the athlete, reflecting the design and delivery of

286 youth sport as well as the norms associated with and meanings ascribed to sport participation.

287 Three primary contexts within the environmental subsystem that may influence or be influenced 288 by young athletes are organizations, communities, and societies.

The most proximal context to athletes, and to the families and teams in which they are

290 embedded, is the organization. Organizations are the entities (e.g., academies, clubs, schools, 
291 municipal entities, for-profit and not-for-profit businesses) that design and deliver sport to youth

292 (Wagstaff, 2017, 2019). Perhaps the most pervasive line of organizational research in sport

293 targets the ways organizations impose numerous demands (i.e., stressors) on athletes and the

294 persons with whom athletes regularly interact (see Arnold et al., 2017). Many organizations that

295 offer sport seek to provide guidance regarding their missions, standards, and cultures to reduce

296 the demands faced by athletes and others, while developing opportunities for persons within the

297 organization to thrive. In recent years, this has included a focus on safe sport principles tied to

298 prevention of injury and abuse (Johnson et al., 2020; Mountjoy et al., 2020).

299 Utilizing a systems lens affords researchers the opportunity to acknowledge the presence

300 of feedback loops, as well as the narratives and metaphors people use to describe their

301 organizations. As such, researchers should consider how organizations design and deliver sport

302 opportunities for youth based on their missions, standards, and cultures, as well as the ways they

303 may be shaped by the parents, coaches, and other stakeholders who contribute to their operation

304 (Legg et al., 2016; Maitland et al., 2015). For instance, explorations of the structure, boundaries,

305 power, hierarchy, function, resource and information sharing, and subgrouping within

306 organizations might provide valuable insights into youth sport environments as interconnected,

307 living human systems. Initial attempts to conduct research in youth sport have largely failed to

308 attend to the impact athletes, and the persons and contexts that surround them, have on the

309 organizations in which they participate and vice versa in an iterative and transactional manner.

310 This gap may be addressed by incorporating organizational and systems-based thinking within

311 more established research lines on parents, siblings, peers, and coaches. In turn, a fuller

312 appreciation may be gained regarding the important role organizations play in such complex

313 systems. 
The interaction of parents, siblings, peers, and coaches within organizations occurs

315 differently across communities. For example, research indicates that towns with fewer than

316100,000 inhabitants may possess unique features related to community size and behavior patterns

317 of youth that are conducive to athletes' sustained engagement in sport (Turnnidge et al., 2014).

318 In terms of the physical environment, smaller communities provide youth with more space for

319 unorganized physical activity and sports with peers (Balish \& Côté, 2014). However, this is

320 balanced by the fact that larger communities often provide youth with increased accessibility,

321 exposure, and competition (Grieve \& Sherry, 2012). From a behavioral perspective, smaller

322 cities may provide integrated approaches to sport participation that foster more engagement from

323 parents, siblings, peers, and coaches whereas larger cities may offer a broader cross-section of

324 activities and competitive trajectories (Surya et al., 2012). Finally, the size of a community has

325 the potential to impact the value placed on positive social norms (e.g., purposeful mentoring,

326 prosocial behavior, communal child-rearing) and the ways parents, coaches, and organizations

327 design and deliver sport (Bale, 2003; Balish \& Côté, 2014; Fraser-Thomas et al., 2010;

328 Turnnidge et al., 2014).

329 Communities establish and fortify the norms associated with sport participation while

330 also providing support at the group level and fostering a sense of belongingness among

331 individuals. This is often referred to as sense of community, and is vital because it fulfills an

332 innate human need for relatedness (McMillan \& Chavis, 1986; Sarason, 1974). Because youth

333 have been shown to benefit in myriad ways from increased sense of community, sport is often

334 championed as a means to enhance personal and community development (Warner \& Dixon,

335 2011, 2013; Warner et al., 2012). Specifically, sense of community has been linked to outcomes

336 such as better health (e.g., Warner et al., 2017) and fewer delinquent behaviors (e.g., Battistich \& 
337 Hom, 1997). Given the potential range of characteristics (e.g., size, initiatives, access,

338 infrastructure) that can impact how communities support youth in sport, as well as community

339 factors that shape how sport is designed and delivered, it is critical to understand how

340 communities fit within the environmental subsystem and broader youth sport system.

341 Societies shape the meanings that individuals, and the persons and contexts that surround

342 them, give to athletes' behaviors, attitudes, experiences, and outcomes in youth sport, and how

343 they integrate those meanings into norms for sport participation and ultimately the design and

344 delivery of sport (Bowers \& Green, 2013). For example, in societies characterized by socio-

345 economic inequality, sports for youth from wealthier families tend to focus on skills and future

346 opportunities (e.g., college and/or professional participation), whereas programs for youth from

347 lower income families tend to focus on social control and personal deficit reduction (Coakley,

348 2002; Whitley et al., 2019). It is important to recognize that the perceived significance of youth

349 sport in societies depends on popular beliefs about the connection between sport involvement

350 and athletes' psychosocial development, social acceptance, and the achievement of educational

351 and occupational success.

352 Youth sport is generally designed and delivered in ways that reflect and reaffirm the

353 traditions and values that are important in a society; however, these values and traditions can be

354 expressed in positive or negative ways and can be inclusive or exclusive in nature. Importantly, it

355 is usually assumed that the lessons taught, and thought to be learned, in youth sport reflect and

356 reaffirm those traditions and values by way of various feedback loops (Coakley, 1983). As an

357 example, in Western societies where individualism is valued, youth sport is generally designed

358 and delivered in ways that place importance on characteristics such as independence, toughness,

359 competition, achievement, and self-reliance. It is also assumed that athletes who demonstrate 
360 these characteristics will have success, and thus confirm these characteristics as important within

361 the society (see Bondin et al., 2020; Fine, 1987; Goodman, 1979; Mrozek, 1983).

362 Whether youth sport is subsidized by the government, its constituent communities, or

363 individual public or private organizations varies across societies and has the potential to impact

364 youth behaviors, attitudes, experiences, and outcomes in sport. For example, the structure of

365 youth sport in China is shaped by the federal government. State policy emphasizes elite sport

366 training among youth who are strategically selected for programs. Alternatively, the design and

367 delivery of sport in Japan is closely tied to physical education in the schools. In much of Europe,

368 Australia, and New Zealand, youth sport is linked to school-based physical education or

369 sponsored by local sport clubs that are age-integrated and focused on participation in one or

370 more sports around which the club and the social lives of its members are organized. Developing

371 countries often have limited public or private resources for youth sport, and the programs that do

372 exist may be sponsored through the outreach of non-governmental organizations from wealthier

373 societies. Developing countries that prioritize resources for youth sport (e.g., India, Kenya, South

374 Africa) tend to organize them around externally determined solutions to perceived cultural and

375 socialization deficits of its youth, with limited long-term impact (Whitley et al., 2019).

$376 \quad$ Youth sport programs in the United States have traditionally been associated with

377 communities (e.g., through parks and recreation departments) and/or organizations (e.g., Little

378 League Baseball) until age 12 or 13, after which sport is often linked to public school systems.

379 This model subsidizes (at least in part) the design and delivery of sport through state or

380 municipal tax dollars, and highlights the inherent value of sport as a public good. Increasingly,

381 however, youth sport is being designed and delivered by entities other than communities and

382 schools, and thus reflects the diverse missions of sponsors ranging from for-profit businesses to 
383 non-profit organizations and local youth sport entrepreneurs. It can be argued, therefore, that

384 youth sport is becoming fragmented, with little continuity across organizations, communities,

385 and societies. Additionally, it appears that when the livelihoods of the adults who control and

386 coach youth sports depend on fees paid by families, programs are organized and marketed to

387 meet the financial missions of organizers and coaches, and the goals of fee-paying parents, rather

388 than the overall developmental needs of youth (Coakley, 2002, 2010; Hyman, 2012).

\section{Designing Future Research to Integrate the Subsystems}

Our aim is to outline a heuristic model that facilitates movement toward an integrated

391 understanding of the youth sport system. In pursuing this aim, the previous sections not only

392 detail that parents, siblings, peers, coaches, organizations, communities, and societies may

393 influence and be influenced by athletes' behaviors, attitudes, experiences, and outcomes in youth

394 sport, but how scholars might think of these persons and contexts as systemic and interrelated

395 across development. In highlighting the key constructs and connections within and across the

396 family, team, and environmental subsystems, we forward a heuristic model of the youth sport

397 system in Figure 1. It showcases key constructs related to the persons and contexts within youth

398 sport, but is not intended to be a comprehensive exposition of the many ways these persons and

399 contexts might interact. In youth sport, families, teams, and contexts should be viewed as

400 integrated and responsive to one another. We therefore hope the model encourages a range of

401 sport psychology and social science researchers to design and execute research in a more

402 integrated way within and across the family, team, and environmental subsystems. This means

403 not just seeking a greater understanding of athletes and the persons and contexts that surround

404 them, but of the myriad processes that have the potential to influence or be influenced by athletes'

405 behaviors, attitudes, experiences, and outcomes over the course of development. 
Depicted by the curved outer shell of the model, societal factors are the most distal context within the youth sport system. Much of our understanding of youth sport comes from research conducted in Western and/or industrialized countries with relatively educated and

409 affluent persons. These societies afford the necessary resources (e.g., time, money, knowledge)

410 to engage in youth sport in an organized way. In light of this, our model calls researchers to

411 account for the many diverse ways sport is enacted, interpreted and experienced in other

412 societies. Societal factors are important in this regard, as they shape the meanings we give to

413 participation in sport. More inclusive future research is critical to a full understanding of the

414 youth sport system. Our model provides a potential starting point for scholars who wish to

415 understand the importance of, and the traditions associated with, youth sport in other societies.

416 Work in this area could target the range of societal values associated with sport participation, and 417 the policies that shape the socialization of athletes, parents, siblings, peers, and coaches.

418 An important aspect of the model to be explored in future research will be how societies 419 impact athletes' behaviors, attitudes, experiences, and outcomes. Questions originating from this 420 level of the model might include: (a) how do societal traditions impact the design and delivery of 421 youth sport by way of community initiatives and organizational missions? (b) in what types of 422 societies does the creation of youth sport policy impact community infrastructure, organizational 423 standards, and athlete behavior (e.g., participation rates, sport choice)? and (c) how do societal 424 resources (e.g., relative affluence versus non-affluence) impact organizational opportunities for, 425 and demands on, athletes, coaches, and parents? Importantly, future research questions in this 426 domain should be developed in light of evidence that societies define and engage in youth sport 427 in varying ways (Messner \& Musto, 2016). Ethnographic research utilizing retrospective surveys, 428 interviews, and the archival analysis of national, regional, local, and personal records may be 
429 well-positioned to address questions pertaining to societal effects on athletes' behaviors, attitudes,

430 experiences, and outcomes over time in youth sport. This might be of particular interest to

431 scholars who are investigating the legal aspects (e.g., protections of civil liberties, safe sport

432 initiatives, liability concerns) that shape youth sport in various cultures. Thoughtfully

433 constructed comparative research could afford scholars the opportunity to examine similarities

434 and differences across multiple societies.

435 Just beneath societies in the model exist communities. Empirical work in youth sport has

436 largely neglected to account for the roles communities play in the norms associated with

437 participation in youth sport. This is surprising because communities, more than societies at large,

438 have the potential to shape or be shaped by young athletes' (and other persons') behaviors,

439 attitudes, experiences, and outcomes in sport. Typically, community level influences are driven

440 by the size of a community, the initiatives and support it offers persons who engage in youth

441 sport, and the access and infrastructure that define how sports are engaged in (Ballish \& Côté,

442 2014). Community factors therefore play an important role in the short- and long-term

443 developmental outcomes experienced by athletes.

444 An important factor to examine in future research will be how communities impact

445 family and team subsystems via organizations. Questions originating from this level of the model

446 might include: (a) how do community initiatives impact the design and delivery of sport by

447 organizations? (b) in what ways can community infrastructure shape the sport opportunities

448 provided by organizations to the athletes who participate? and (c) how do interactions within the

449 team subsystem (among, athletes, peers, and coaches) and family subsystem (among athletes,

450 parents, and siblings) differ across organizations within a community? Future research should be

451 designed in light of knowledge that communities are shaped by broader society and also have the 
452 potential to shape and be shaped by families, teams, and organizations. Case-study research 453 utilizing multiple methodologies may be well-positioned to highlight these feedback loops.

At the center of the integrated model lie organizations, and it is organizations that serve

455 as an intermediary between the distal and proximal factors that can influence or be influenced by

456 athletes' behaviors, attitudes, experiences, and outcomes in youth sport. This central position in

457 the model is a result of organizations being formed in view of the broader roles played by

458 societies and communities, while also being charged with creating the direct contexts in which

459 athletes, families, and teams participate. Driven by feedback loops, organizations such as

460 academies, clubs, schools, municipal entities, places of worship, and businesses foster

461 opportunities for youth and serve as gatekeepers to the missions, standards, and cultures by

462 which success, failure, and development are judged, while also being shaped by the parents and 463 coaches who contribute to their functioning (Legg et al., 2016).

464 Considering extant research on organizations in youth sport (see Wagstaff, 2017, 2019),

465 an important direction for future work will be to address the potential feedback loops among

466 persons and organizations within the youth sport system. Questions stemming from this level of

467 the model might include: (a) what organizational factors foster or limit the enhancement of

468 coaches' professional and interpersonal knowledge? (b) how do the demands placed on coaches

469 and parents by organizations impact the team and family subsystems at various developmental

470 levels of sport? and (c) how is an organization's design and delivery of sport shaped by aspects

471 of the community (e.g., infrastructure and access) as well as attributes of the athletes it serves

472 (e.g., age, gender, race/ethnicity, sexuality, socioeconomic status, identity, ability, etc.)?

473 Future research in this domain should be developed considering that parents and coaches

474 are largely responsible for structuring the organizations that offer youth sport, especially those 
475 that serve younger children at the recreational level (Project Play, 2015). Program evaluation

476 research incorporating focus groups, surveys, observation, and daily diaries with athletes,

477 parents, and coaches could be especially valuable in capturing the dynamic and reciprocal

478 relationships persons in the youth sport system have with sport-delivering organizations in their

479 respective communities. Additional research targeting feedback loops in the youth sport system

480 could be designed to examine the ways athletes "give back" to youth sport when they move into

481 new and different roles (e.g., as former athletes, parents, volunteers, coaches, or officials). Lerner

482 and colleagues' 6Cs model could contribute to the conceptual extension of this developmental

483 knowledge, wherein the $6^{\text {th }} \mathrm{C}$ represents the concept of contribution to one's self, family,

484 community, and society (Lerner 2004; Lerner et al., 2005).

485 The four "gears" within our model represent the most proximal persons to the athlete

486 within the youth sport system: parents, siblings, peers, and coaches. The gears contain

487 descriptive characteristics, words, and phrases that highlight salient concepts from an

488 international body of literature. These concepts, in many cases, represent proximal processes that

489 take place on a daily basis among these persons (García Bengoechea, 2002). In line with

490 Bronfenbrenner's (2005) conceptualization of person characteristics, proximal processes are

491 guided by an athlete's age, gender, race/ethnicity, sexuality, socioeconomic status, identity,

492 ability, and aspirations, among other factors. Importantly, we acknowledge that the personal

493 characteristics of parents, siblings, peers, and coaches also shape athletes' behaviors, attitudes,

494 experiences, and outcomes in youth sport. Although not explicitly specified in Figure 1, the

495 personal characteristics of parents, siblings, peers, and coaches should also be considered in

496 work informed by our model. We also acknowledge that the same "system" is not experienced

497 by all athletes. As examples, family subsystem interactions occur differently if there are no 
498 siblings in the household, in a single-parent household, or if the athlete is living and training 499 away from family (Wright et al., in press).

501 interactions with other persons evolves over the course of development. Specifically, athletes

502 experience (1) shifts in the sources of competence information that they prioritize, (2) plasticity

503 in the development and maintenance of relationships, and thus how they interact with other

504 persons, and (3) the dynamic roles and involvement of other persons (see Côté \& Vierimaa,

505 2014). These factors change from toddlerhood through middle-to-late adolescence and are thus

506 highlighted by the athlete (depicted with a ball) moving from left to right across the black arrow

507 at the bottom of the model. Despite normative trends, it is important to note that the

508 developmental salience of athletes' relationships with parents, siblings, peers, and coaches is not

509 always linear, predictable, or mutually exclusive. Thus, as an example, the family subsystem has

510 the potential to be impactful well beyond childhood, even if it is expected that the team

511 subsystem might be of particular importance as a sport career evolves.

512 There are a wide range of research questions that could be addressed within this portion

513 of the model. Of particular interest is the interrelationship of the family and team subsystems via

514 the athlete. Questions situated within this portion of the model might include: (a) to what extent

515 are parents' goals for their children in youth sport associated with coaches' expectations, and

516 how is this shaped by the athlete's age and gender? (b) how do athletes balance social

517 comparison to siblings and peers, and how does this change over time? and (c) what impact does

518 an athlete's ability have on the way parents and coaches engage with the athlete's siblings and

519 peers in sport? Future questions attending to the integration of the family and team subsystems

520 should be developed considering evidence that proximal processes are not static and constant, 
521 but dynamic and changing (Côté, 1999), and in light of the fact that they may vary across

522 communities and societies. Developmentally-informed research is needed to capture the nuance

523 of athletes' behaviors, attitudes, experiences, and outcomes over time in youth sport (Smith et al., 524 2012).

525 In examining the model, it is important to acknowledge some of the conceptual work that

526 preceded it. In the bottom half of the model, we view members of the family and team

527 subsystems (i.e., parents, siblings, peers, and coaches) as interconnected. In doing so, our model

528 builds directly from a systems perspective, and specifically its tenet of holism (Broderick, 1993).

529 In depicting parents, siblings, peers, and coaches as "gears" engaging in dyadic reciprocal

530 relationships with the athlete (and in some cases each other), the model pays homage to work by

531 Bell (1968) and others who highlighted the feedback loops that drive socialization process within

532 close relationships. Last, our depiction of the athlete "ball" is informed, in part, by person

533 characteristics as set forth in Bronfenbrenner's (2005) PPCT model of human development.

534 Depicting the ball moving from left to right, spanning a time period from toddlerhood through

535 middle-to-late adolescence, aligns with Côté's developmental model of sport participation (see

536 Côté \& Vierimaa, 2014) and personal assets framework for sport (Côté et al., 2019), as well as

537 the time component of Bronfenbrenner's PPCT model. It also highlights that athletes' behaviors,

538 attitudes, experiences, and outcomes are not static, but instead change and are negotiated over

539 time. This aligns with the systems perspective, and specifically its tenet of roles.

540 In the top half of the model, the environmental subsystem is comprised of three contexts:

541 organizations, communities, and societies. Our conceptualization of these contexts builds from

542 present understanding of organizational psychology (Wagstaff, 2019), community psychology

543 (Warner, 2016), and sport sociology (Coakley, 2016), but also broadens the scope of what 
544 typically has been considered within the youth sport system. In our model, the family and team

545 subsystems are represented as being nested within the broader environmental subsystem. The

546 three subsystems, collectively, are posited to influence and be influenced by athletes via the

547 structure of, and daily interactions among, the persons and contexts that surround them.

\section{Challenges and Limitations}

Approaching youth sport through an integrated lens presents several challenges and

550 limitations. Most obviously, it can be difficult to integrate the higher levels of the model into

551 everyday research and practice. At the broadest level, for example, cross-cultural issues may

552 shape how the model is interpreted and applied in different youth sport contexts around the

553 world (Ryba et al., 2013; Si \& Lee, 2007). Certain aspects of our model may be more salient in

554 societies or communities where competitive sport is more widely practiced.

An additional consideration is that our model is delimited to persons who interact with

556 young people in the youth sport context. This includes parents and siblings within the family

557 subsystem and peers and coaches within the team subsystem. Given the model's focus on the

558 youth sport system, it does not account for other potentially important persons, such as teachers,

559 mentors, and peers who are not teammates. These persons also can influence and be influenced

560 by the athlete's sport participation. Future research, therefore, could target the direct and indirect

561 impacts of these persons on children's sport-related outcomes and experiences.

562 Our model does not explicitly account for conflict that may be introduced within or

563 across the various subsystems. For example, athletes are often forced to reconcile differences

564 between their own goals and the goals their parents or coaches might have for their participation

565 in sport. The process of reconciliation can be further shaped by athletes' interpretation of peer

566 and sibling influences, as well as the broader expectations of their sport-delivering individual, 
567 organization, or community. Moving forward, researchers might view conflict within or across

568 the family, team, and environmental subsystems through a lens of disequilibrium, another tenet

569 of the systems perspective (Broderick, 1993). Disequilibrium is the state of imbalance

570 experienced by an individual when new experiences cannot be understood or easily

571 accommodated (Berger, 2005). Applying this tenet to future research on the youth sport system

572 would further extend theoretically grounded understanding of the independent and simultaneous

573 effects various persons and contexts have within the youth sport system.

574 Finally, the potential impact of our model on current thinking in the field of kinesiology

575 may be discounted because our model speaks to concepts not usually measured or discussed in

576 kinesiology journals. The environmental subsystem is understudied in kinesiology research,

577 especially as it relates to the social, cognitive, and emotional aspects of sport and physical

578 activity behavior in young people. However, incorporating this subsystem in our model orients

579 kinesiologists to its importance and potential for advancing knowledge. Zelaznik and Harper

580 (2007) contend that the sociological, anthropological, and philosophical aspects of sport and all

581 other forms of human movement should be of central interest to kinesiologists who aim to

582 promote intrinsic motivation for physical activity. We hope that our model increases

583 consideration of these components of the youth sport system.

\section{Conclusion}

In presenting this heuristic model of the youth sport system, we have extended past work

586 championing theoretical integration (e.g., García Bengoechea, 2002) and have highlighted

587 potentially valuable research questions. Moreover, we have provided various considerations for

588 scholars who wish to examine the intersections of persons and contexts in youth sport. In doing

589 so, we hope to move sport scientists and leaders toward a systemic and interdisciplinary 
590 understanding of the parents, siblings, peers, coaches, organizations, communities, and societies

591 that surround athletes in youth sport. Conversely, other aspects of the model may be more salient

592 where lifetime sports are practiced in less organized or competitive settings. In all cases,

593 conceptually-driven, interdisciplinary work attending to the systems perspective tenets of holism,

594 feedback loops, and roles remains best positioned to capture the nuanced ways persons and

595 contexts influence and are influenced by athletes in youth sport. We believe that such work has

596 the potential to meaningfully impact theory and practice with regard to the persons and contexts

597 that comprise the youth sport system. 


\section{References}

599

600

601

602

603

604

605

606

607

608

609

610

611

612

613

614

615

616

617

618

619

Adams, A., \& Carr, S. (2019). Football friends: Adolescent boys' friendships inside an English professional football (soccer) academy. Soccer \& Society, 20, 471-493.

Álvarez, M. S., Balaguer, I., Castillo, I., \& Duda, J. L. (2009). Coach autonomy support and quality of sport engagement in young soccer players. The Spanish Journal of Psychology, $12,138-148$.

Arnold, R., Fletcher, D., \& Daniels, K. (2017). Organisational stressors, coping, and outcomes in competitive sport. Journal of Sports Sciences, 35, 694-703.

Babkes, M. L., \& Weiss, M. R. (1999). Parental influence on children's cognitive and affective responses to competitive soccer participation. Pediatric Exercise Science, 11, 44-62.

Bale, J. (2003). Sports geography (2 ${ }^{\text {nd }}$ ed.). Routledge.

Balish, S., \& Côté, J. (2014). The influence of community on athletic development: An integrated case study. Qualitative Research in Sport, Exercise and Health, 6, 98-120.

Battistich, V., \& Hom, A. (1997). The relationship between students' sense of their school as a community and their involvement in problem behaviors. American Journal of Public Health, 87, 1997-2001.

Bell, R. Q. (1968). A reinterpretation of the direction of effects in studies of socialization. Psychological Review, 75, 81-95.

Bell, N. J., Avery, A. W., Jenkins, D., Feld, J., \& Schoenrock, C. J. (1985). Family relationships and social competence during late adolescence. Journal of Youth and Adolescence, 14, 109-119.

Berger, K. S. (2005). The developing person through the life span (6th ed.). Worth. 
620 621

622

623

624

625

626

627

628

629

630

631

632

633

634

635

636

637

638

639

640

Blazo, J. A., Czech, D. R., Carson, S., \& Dees, W. (2014). A qualitative investigation of the sibling sport achievement experience. The Sport Psychologist, 28, 36-47.

Blazo, J. A., \& Smith, A. L. (2018). A systematic review of siblings and physical activity experiences. International Review of Sport and Exercise Psychology, 11, 122-159.

Bondin, V. I., Luybetsky, N. P., Schalohyan, S. I., Garasimov, M. V., \& Samygin, S. I. (2020). Sport in the context of globalization. In E. G. Popkova \& B. S. Sergi (Eds.), Artificial intelligence: Anthropogenic nature vs. social origin (pp. 237-247). Springer.

Bowers, M. T., \& Green, B. C. (2013). Reconstructing the community based youth sport experience: How children derive meaning from unstructured and organized settings. Journal of Sport Management, 27, 422-438.

Brawley, L. R., \& Martin, K. A. (1995). The interface between social and sport psychology. The Sport Psychologist, 9, 469-497

Broderick, C. B. (1993). Understanding family process: Basics of family systems theory. Sage.

Bronfenbrenner, U. (2005). Making human beings human: Bioecological perspectives on human development. Sage.

Bruner, M. W., Balish, S. M., Forrest, C., Brown, S., Webber, K., Gray, E., McGuckin, M., Keats, M. R., Rehman, L., \& Shields, C. A. (2017). Ties that bond: Youth sport as a vehicle for social identity and positive youth development. Research Quarterly for Exercise and Sport, 88, 209-214.

Brustad, R. J. (2010). The role of family in promoting physical activity. President's Council on Physical Fitness and Sports Research Digest, 10, 1-8. 
641 642

643

644

645

646

647

648

649

650

651

652

653

654

655

656

657

658

659

660

661

662

663

Burgess, N. S., Knight, C. J., \& Mellalieu, S. D. (2016). Parental stress and coping in elite youth gymnastics: An interpretative phenomenological analysis. Qualitative Research in Sport, Exercise and Health, 8, 237-256.

Chelladurai, P. (2007). Leadership in sports. Handbook of Sport Psychology, 3, 113-135.

Cicirelli, V. G. (1995). Sibling relationships across the lifespan. Plenum Press.

Coakley, J. (1983). Play, games and sports: Developmental implications for young people. In J. C. Harris \& R. J. Park (Eds.), Play, games and sports in cultural contexts (pp. 431-450). Human Kinetics.

Coakley, J. (2002). Using sports to control deviance and violence among youths: Let's be critical and cautious. In M. Gatz, M. A. Messner, \& S. J. Ball-Rokeach (Eds.), Paradoxes of youth and sport (pp. 13-30). State University of New York Press.

Coakley, J. (2010). The "logic" of specialization: Using children for adult purposes. Journal of Physical Education, Recreation and Dance, 81, 16-18.

Coakley, J. (2016). Youth sports in the United States. In K. Green \& A. Smith (Eds.), Handbook of youth sport (pp. 84-97). Routledge.

Coatsworth, J. D., \& Conroy, D. E. (2009). The effects of autonomy-supportive coaching, need satisfaction, and self-perceptions on initiative and identity in youth swimmers. Developmental Psychology, 45, 320-328.

Côté, J. (1999). The influence of the family in the development of talent in sport. The Sport Psychologist, 13, 395-417.

Côté, J., Allan, V., Turnnidge, J., Vierimaa, M., \& Evans, M. B. (2019). Youth talent development in sport. In T. S. Horn \& A. L. Smith (Eds.), Advances in sport and exercise psychology (4 ${ }^{\text {th }}$ ed., pp. 467-482). Human Kinetics. 
664 Côté, J., \& Gilbert, W. (2009). An integrative definition of coaching effectiveness and expertise. International Journal of Sports Science \& Coaching, 4, 307-323.

Côté, J., Salmela, J. H., Trudel, P., Baria, A., \& Russell, S. (1995). The coaching expert model: A grounded assessment of expert gymnastic coaches' knowledge. Journal of Sport \& Exercise Psychology, 17, 1-17.

Côté, J. \& Vierimaa, M. (2014). The developmental model of sport participation: 15 years after its first conceptualization. Science \& Sport, 29, S63-S69.

Cox, A. E., \& Ullrich-French, S. (2010). The motivational relevance of peer and teacher relationship profiles in physical education. Psychology of Sport and Exercise, 11, 337344.

Dorsch, T. E., King, M., Dunn, C. R., Osai, K. V., \& Tulane, S., (2017). The impact of evidencebased parent education in organized youth sport: A pilot study. Journal of Applied Sport Psychology, 29, 199-214.

Dorsch, T. E., Smith, A. L., \& McDonough, M. H. (2015a). Early socialization of parents through organized youth sport. Sport, Exercise, and Performance Psychology, 4, 3-18. verbal sideline behavior in organized youth sport. Sport, Exercise, and Performance Psychology, 4, 19-35. 
685 686

687

Dorsch, T. E., Vierimaa, M., \& Plucinik, J. (2019). A citation network analysis of research on parent-child interactions in youth sport. Sport, Exercise, and Performance Psychology, 8, 145-162.

Duda, J. L. (1999). The motivation to study motivation: Goal perspectives and their influence. In G. G. Brannigan (Ed.), The sport scientist: Research adventures (pp. 57-73). Longman.

Duncan, S. C., Duncan, T. E., \& Stryker, L. A. (2005). Sources and types of social support in youth physical activity. Health Psychology, 24, 3-10.

Dunn, J. (2007). Siblings and socialization. In J. Grusec \& P. Hastings (Eds.), Handbook of socialization: Theory and research (pp. 309-329). Guilford Press.

Erickson, K. \& Côté, J. (2016). A season-long examination of the motivational tone of coachathlete interactions in youth sport. Psychology of Sport and Exercise, 22, 264-272.

Evans, J., \& Roberts, G. C. (1987). Physical competence and the development of children's peer relations. Quest, 39, 23-35.

Fagan, A. A., \& Najman, J. M. (2005). The relative contributions of parental and sibling substance use to adolescent tobacco, alcohol, and other drug use. Journal of Drug Issues, 35, 869-883.

Fine, G. A. (1987). With the boys: Little league baseball and preadolescent culture. University of Chicago Press.

Fraser-Thomas, J. L., Côté, J., \& Deakin, J. (2005). Youth sport programs: An avenue to foster positive youth development. Physical Education \& Sport Pedagogy, 10, 19-40.

Fraser-Thomas, J. L., Côté, J., \& MacDonald, D. J. (2010). Community size and sport settings: Examining developmental assets and sport withdrawal. Physical Health Education Academic Journal, 2, 1-9. 
708 Fredricks, J. A., \& Eccles, J. S. (2004). Parental influences on youth involvement in sports. In M. R. Weiss (Ed.), Developmental sport and exercise psychology: A lifespan perspective (pp.

711 Furman, W., \& Buhrmester, D. (1985). Children's perceptions of the qualities of sibling relationships. Child Development, 56, 448-461.

713 García Bengoechea, E. (2002). Integrating knowledge and expanding horizons in developmental sport psychology: A bioecological perspective. Quest, 54, 1-20.

715 García Bengoechea, E., \& Johnson, G. M. (2001). Ecological systems theory and children’s development in sport: Toward a process-person-context-time research paradigm. Avante,

718 Gardner, L. A., Magee, C. A., \& Vella, S. A. (2016). Social climate profiles in adolescent sports: Associations with enjoyment and intention to continue. Journal of Adolescence, 52, 112123.

721 Goodman, C. (1979). Choosing sides: Playground and street life on the lower east side.

$722 \quad$ Schocken Books.

723 Gould, D. (2019). The current youth sport landscape: Identifying critical research issues.

724 Kinesiology Review, 8, 150-161.

725 Grieve, J., \& Sherry, E (2012). Community benefits of major sport facilities: The Darebin International Sports Centre. Sport Management Review, 15, 218-229.

727 Harwood, C. G., \& Knight, C. J. (2015). Parenting in youth sport: A position paper on parenting 728 expertise. Psychology of Sport and Exercise, 16, 24-35.

729 Hellstedt, J. C. (1987). The coach/parent/athlete relationship. The Sport Psychologist, 1, 151-160. 
Holt, N. L., Knight, C. J., \& Zukiwski, P. (2012). Female athletes' perceptions of teammate conflict in sport: Implications for sport psychology consultants. The Sport Psychologist, $26,135-154$.

Holt, N. L., Tamminen, K. A., Black, D. E., Sehn, Z. L., \& Wall, M. P. (2008). Parental involvement in competitive youth sport settings. Psychology of Sport and Exercise, 9, 663-685.

Horn, T. S., \& Horn, J. L. (2007). Family influences on children's sport and physical activity participation, behavior, and psychosocial responses. In G. Tenenbaum \& R. C. Eklund (Eds.), Handbook of sport psychology (pp. 685-711). Wiley.

Horne, T., \& Carron, A. V. (1985). Compatibility in coach-athlete relationships. Journal of Sport Psychology, 7, 137-149.

Hulteen, R. M., Smith, J. J., Morgan, P. J., Barnett, L. M., Hallal, P. C., Colyvas, K., \& Lubans, D. R. (2017). Global participation in sport and leisure-time physical activities: A systematic review and meta-analysis. Preventive Medicine, 95, 14-25.

Hyman, M. (2012). Until it hurts: America's obsession with youth sports and how it harms our kids. Beacon Press.

Jackson, B., Beauchamp, M. R., \& Knapp, P. (2007). Relational efficacy beliefs in athlete dyads: An investigation using actor-partner interdependence models. Journal of Sport \& Exercise Psychology, 29, 170-189.

Jackson, B., Gucciardi, D. F., Lonsdale, C., Whipp, P. R., \& Dimmock, J. A. (2014). “I think they believe in me": The predictive effects of teammate-and classmate-focused relationinferred self-efficacy in sport and physical activity settings. Journal of Sport \& Exercise Psychology, 36, 486-505. 
753 Johnson, N., Hanna, K., Novak, J., \& Giardino, A. P. (2020). US Center for SafeSport:

754 Preventing abuse in sports. Women in Sport and Physical Activity Journal, 28, 66-71.

755 Jowett, S. (2005). On repairing and enhancing the coach-athlete relationship. In S. Jowett \& C.

756 Harwood (Eds.), The psychology of coaching (pp. 14-26). British Psychological

$757 \quad$ Association.

758 Jowett, S., \& Timson-Katchis, M. (2005). Social networks in sport: Parental influence on the coach-athlete relationship. The Sport Psychologist, 19, 267-287

760 Knight, C. J., \& Holt, N. L. (2014). Parenting in youth tennis: Understanding and enhancing children's experiences. Psychology of Sport and Exercise, 15, 155-164.

762 Legg, J., Snelgrove, R., \& Wood, L. (2016). Modifying tradition: Examining organizational change in youth sport. Journal of Sport Management, 30, 369-381.

Lerner, R. M. (2004). Liberty: Thriving and civic engagement among American youth. Sage.

765 Lerner R. M., Lerner J. V., Almerigi J., Theokas C., Phelps E., Gestsdottir S., Naudeau, S., Jelicic, H., Alberts, A., Ma, L., Smith, L. M., Bobek, D. L., Richman-Raphael, D., Simpson, I., Christiansen, E. D., \& von Eye, A. (2005). Positive youth development, participation in community youth development programs, and community contributions

Maitland, A., Hills, L. A., \& Rhind, D. J. (2015). Organisational culture in sport - A systematic review. Sport Management Review, 18, 501-516.

773 McHale, S. M., Updegraff, K. A., \& Whiteman, S. D. (2012). Sibling relationships and influences in childhood and adolescence. Journal of Marriage and Family, 74, 913-930. 
775 McLaren, C. D., Newland, A., Eys, M., \& Newton, M. (2016). Peer-initiated motivational

776

777

778

779

780

781

782

783

784

785

786

climate and group cohesion in youth sport. Journal of Applied Sport Psychology, 29, 88100.

McMillan, D., \& Chavis, D. (1986). Sense of community: A definition and theory. Journal of Community Psychology, 14, 6-23.

Messner, M. A., \& Musto, M. (2016). Child's play: Sport in kids' worlds. Rutgers University Press.

Mountjoy, M., Vertommen, T., Burrows, K., \& Greinig, S. (2020). \#SafeSport: Safeguarding initiatives at the Youth Olympic Games 2018. British Journal of Sports Medicine, 54, 176-182.

Mrozek, D. J. (1983). Sport and American mentality, 1880-1920. University of Tennessee Press.

Newhouse-Bailey, M., Dixon, M. A., \& Warner, S. (2015). Sport and family functioning: Strengthening elite sport families. Journal of Amateur Sport, 1, 1-26.

Nicholson, M., Brown, K., \& Hoye, R. (2013). Sport's social provisions. Sport Management Review, 16, 148-160.

Olympiou, A., Jowett, S., \& Duda, J. L. (2008). The psychological interface between the coachcreated motivational climate and the coach-athlete relationship in team sports. The Sport Psychologist, 22, 423-438.

Osai, K. V., \& Whiteman, S. D. (2017). Family relationships and youth sport: Influence of siblings and parents on youth's participation, interests, and skills. Journal of Amateur Sport, 3, 86-105.

Partridge, J. A., \& Knapp, B. A. (2016). Mean girls: Adolescent female athletes and peer conflict in sport. Journal of Applied Sport Psychology, 28, 113-127. 
Pelletier, L. G., Fortier, M. S., Vallerand, R. J., \& Brière, N. M. (2001). Associations among perceived autonomy support, forms of self-regulation, and persistence: A prospective study. Motivation and Emotion, 25, 279-306.

Project Play (2015). Sport for all, play for life. Washington, DC: Aspen Institute.

Riley, A., \& Smith, A. L. (2011). Perceived coach-athlete and peer relationships of young athletes and self-determined motivation for sport. International Journal of Sport Psychology, 42, 115-133.

Ryba, T. V., Stambulova, N. B., Si, G., \& Schinke, R. J. (2013). ISSP position stand: Culturally competent research and practice in sport and exercise psychology. International Journal of Sport and Exercise Psychology, 11, 123-142.

Sarason, S. B. (1974). The psychological sense of community: Prospects for a community psychology. Jossey-Bass.

Savin-Williams, R. C., \& Berndt, T. J. (1990). Friendship and peer relations. In S. S. Feldman \& G. R. Elliott (Eds.), At the threshold: The developing adolescent (pp. 277-307). Harvard University Press.

Schary, D. P., \& Cardinal, B. J. (2015). Interdisciplinary and intradisciplinary research and teaching in kinesiology: Continuing the conversation. Quest, 67, 173-184.

Si, G. C., \& Lee, H. (2007). Cross-cultural issues in sport psychology research. In S. Jowett, \& D. Lavallee (Eds.), Social psychology in sport (pp. 279-288). Human Kinetics.

Smith, A. L., Dorsch, T. E., \& Monsma, E. V. (2012). Developmentally informed measurement in sport and exercise psychology research. In G. Tenenbaum, R. C. Eklund, \& A. Kamata (Eds.), Measurement in sport and exercise psychology (pp. 131-141). Human Kinetics. 
820 Smith, A. L., Gustafsson, H., \& Hassmén, P. (2010). Peer motivational climate and burnout 821 perceptions of adolescent athletes. Psychology of Sport and Exercise, 11, 453-460.

822 Smith, A. L., Mellano, K. T., \& Ullrich-French, S. (2019). Peers and psychological experiences 823 in physical activity settings. In T. S. Horn \& A. L. Smith (Eds.), Advances in sport and exercise psychology (4 ${ }^{\text {th }}$ ed., pp. 133-150). Human Kinetics.

825 Smith, R. E., \& Smoll, F. L. (2002). Way to go, coach!: A scientifically-proven approach to youth sports coaching effectiveness. Warde Publishers.

827 Smith, S. R., \& Hamon, R. R. (2012). Exploring family theories (3 ${ }^{\text {rd }}$ ed.). Oxford University $828 \quad$ Press.

829 Surya, M., Bruner, M. W., MacDonald, D. J., \& Côté, J. (2012). A comparison of developmental activities of elite athletes born in large and small cities. Physical and Health Education Academic Journal, 4, 1-8.

832 Teques, P., Serpa, S., Rosado, A., Silva, C., \& Calmeiro, L. (2018). Parental involvement in 833 sport: Psychometric development and empirical test of a theoretical model. Current Psychology, 37, 234-249.

835 Thrower, S. N., Harwood, C. G., \& Spray, C. M. (2017). Educating and supporting tennis parents: An action research study. Qualitative Research in Sport, Exercise and Health, 9, 600-618.

837 Turnnidge, J., \& Côté, J. (2017). Transformational coaching workshop: Applying a personcentred approach to coach development programs. International Sport Coaching Journal, 4, 314-325.

840 Turnnidge, J., Hancock, D. J., \& Côté, J. (2014). The influence of birth date and place of development on youth sport participation. Scandinavian Journal of Medicine \& Science in Sports, 24, 461-468. 
843 Ullrich-French, S., \& Smith, A. L. (2006). Perceptions of relationships with parents and peers in 844 youth sport: Independent and combined prediction of motivational outcomes. Psychology

Vazou, S., Ntoumanis, N., \& Duda, J. L. (2006). Predicting young athletes' motivational indices as a function of their perceptions of the coach-and peer-created climate. Psychology of Sport and Exercise, 7, 215-233.

von Bertalanffy, L. (1972). The history and status of general systems theory. Academy of Management Journal, 15, 407-426.

851 Wagstaff, C. R. D. (2017). The organizational psychology of sport: Key issues and practical applications. Routledge.

853 Wagstaff, C. R. D. (2019) A commentary and reflections on the field of organizational sport psychology, Journal of Applied Sport Psychology, 31, 134-146.

Warner, S. (2016). Sport and Sense of Community Theory. In G. B. Cunningham, J. Fink, \& A. Doherty (Eds.), Routledge handbook of theory in sport management (pp. 189-198). Routledge.

858 Warner, S., \& Dixon, M. A. (2011). Understanding sense of community from the athlete's perspective. Journal of Sport Management, 25, 257-271.

860 Warner, S., \& Dixon, M. A. (2013). Sports and community on campus: Constructing a sports experience that matters. Journal of College Student Development, 54, 283-298.

862 Warner, S., Dixon, M. A., \& Chalip, L. C. (2012). The impact of formal versus informal sport: 863 Mapping the differences in sense of community. Journal of Community Psychology, 40, 864 983-1003. 
865 866

867

868

869

870

871

872

873

874

875

876

877

878

879

880

881

882

883

884

885

886

Warner, S., Sparvero, E., Shapiro, S., \& Anderson, A. (2017). Yielding healthy community with sport? Journal of Sport for Development, 5, 41-52.

Weiss, M. R., \& Duncan, S. C. (1992). The relationship between physical competence and peer acceptance in the context of children's sports participation. Journal of Sport \& Exercise Psychology, 14, 177-191.

Weiss, M. R., \& Fretwell, S. D. (2005). The parent-coach/child-athlete relationship in youth sport: Cordial, contentious, or conundrum? Research Quarterly for Exercise \& Sport, 76, 286-305.

Weiss, M. R., Smith, A. L., \& Theeboom, M. (1996). “That's what friends are for:” Children's and teenagers' perceptions of peer relationships in the sport domain. Journal of Sport \& Exercise Psychology, 18, 347-379.

Weiss, M. R., \& Stuntz, C. P. (2004). A little friendly competition: Peer relationships and psychosocial development in youth sport and physical activity contexts. In M. R. Weiss (Ed.), Developmental sport and exercise psychology: A lifespan perspective (pp. 165196). Fitness Information Technology.

Whitley, M. A., Massey, W. V., Camiré, M., Blom, L. C., Chawansky, M., Forde, S., Boutet, M., Borbee, A., \& Darnell, S. C. (2019). A systematic review of sport for development interventions across six global cities. Sport Management Review, 22, 181-193.

Wright, E., Gould, D., \& Erickson, K. (in press). Home away from home: An examination of the billet family experience in junior ice hockey. Journal of Applied Sport Psychology.

Yeh, H. C., \& Lempers, J. D. (2004). Perceived sibling relationships and adolescent development. Journal of Youth and Adolescence, 33, 133-147. 
887 Zelaznik, H. N., \& Harper, W. A. (2007). Skill and physical activity: A central dogma for $888 \quad$ kinesiology. Quest, 59, 163-169.

889 Ziviani, J., Macdonald, D., Ward, H., Jenkins, D., \& Rodger, S. (2006). Physical activity and the 890 occupations of children: Perspectives of parents and children. Journal of Occupational $891 \quad$ Science, 13, 180-187. 


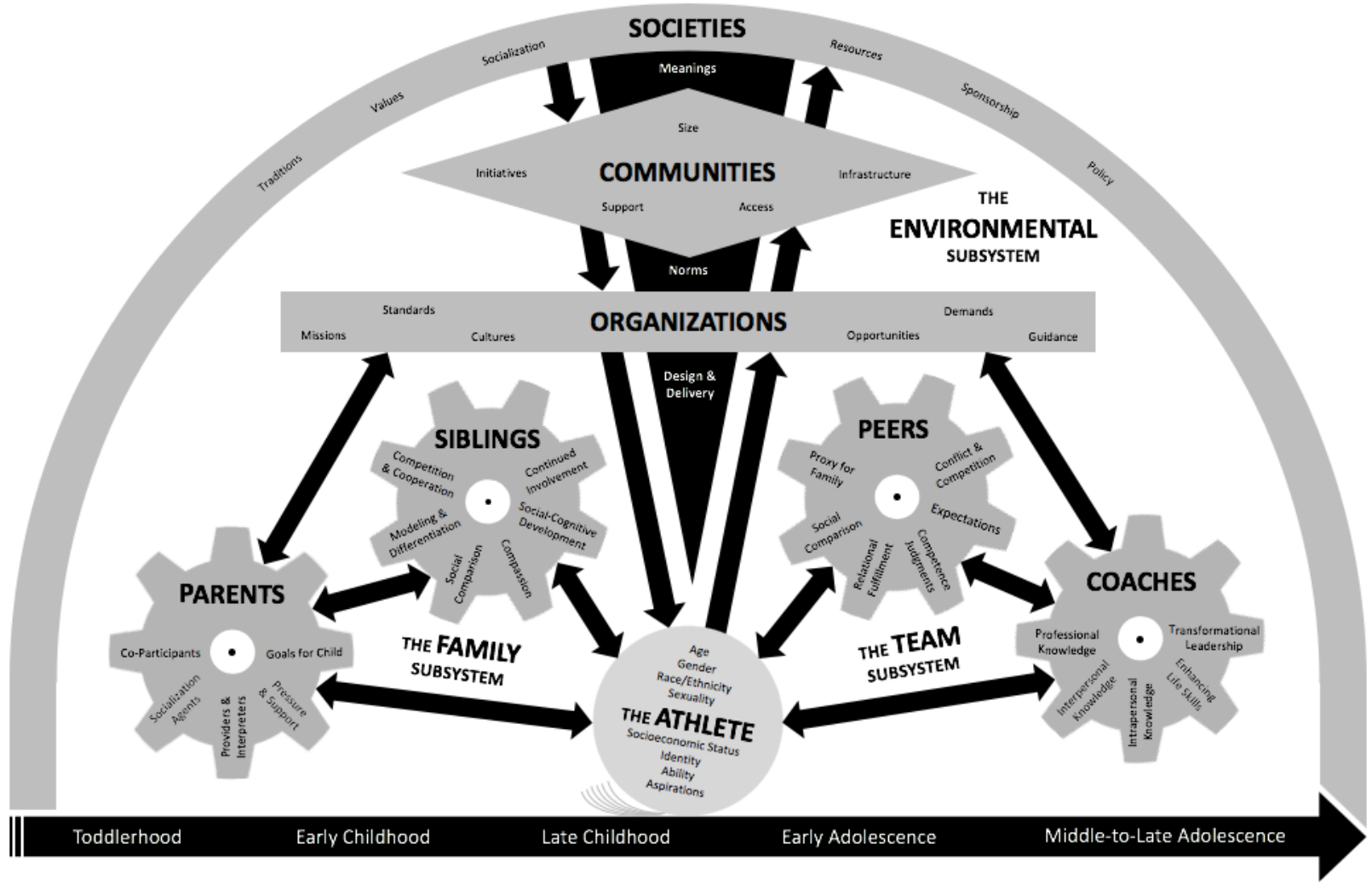

892

893

Figure 1. Heuristic model of the youth sport system and its three interrelated subsystems. 